\title{
Integration of the SHEL Model with the Flight Operational Quality Assurance (FOQA) Program
}

\author{
Dr. James T. Schultz \\ Embry-Riddle Aeronautical University \\ Capt. Scott Forn \\ United States Air Force \\ Dr. Marian C. Schultz \\ University of West Florida
}

\begin{abstract}
The SHEL Model has been used to explore relationships between liveware, environmental, hardware and software factors. This study attempts to integrate Flight Operational Quality Assurance (FOQA) program data with the SHEL model. Aircraft record data that can be used to monitor the human interface within the entire system, plus identify faults and potential failures within the system before a major accident or incident occurs. These data have existed for over four decades, and FOQA offers a way to both analyze and act upon them. The relationships between the SHEL model and FOQA data can help to ensure our nation's skies are the safest and most efficient in the world.
\end{abstract}

One of the challenges in early aviation was the integration of the human and machine interface to accomplish the goal of flight. Over the decades, and now more than a century since the Wright Brothers accomplished the goal, powered aircraft have evolved into machines that barely resemble the Wright Flyer; however, the human element has not changed. Scientists have gained an increased understanding of how humans interact with aircraft, but human beings are still the same as they were when Orville and Wilbur first piloted their flying machine. This study attempts to integrate Flight Operational Quality Assurance (FOQA) program data with the SHEL model.

Aircraft have undergone enormous technological advances in structures, avionics, and automation. Engineers have grappled with concepts such as what information the instruments should transmit, how the controls should be shaped, placed, and respond, and how to "pilot proof", to some extent, the operation of the aircraft systems. A problem, which has always existed in aviation, has been the interface of the human with the environment, procedures, and machine in order to operate in an efficient, timely, and most importantly safe manner. Since two out of every three accidents can be attributed to human error, it becomes apparent that the human portion of the loop requires the greatest concentration of effort to make aviation as safe as possible (Wiener \& Nagel, 1988).

In 1972, Elwyn Edwards developed a method inspired by the well-known conceptual model, which he called SHEL (Marti, Lanzi \& Pucci, 2001). This model details the relationships between the human liveware "L", the machine hardware " $\mathrm{H}$ ", the software " $\mathrm{S}$ ", which encompasses rules, regulations, techniques, and practices, and the environment "E" (Wiener \& Nagel, 1988, p. 11). The model has been utilized to understand the various ergonomic implications associated with flight. For the purposes of this paper, the "SHEL" elements will be referred to as: Crew = "L", Aircraft $=$ "H", Air Traffic Control (ATC), and Federal Aviation Regulations (FARs) = "S", and environmental factors to include wind and weather = "E". When the model is shown pictorially, it appears as shown in Figure 1. 


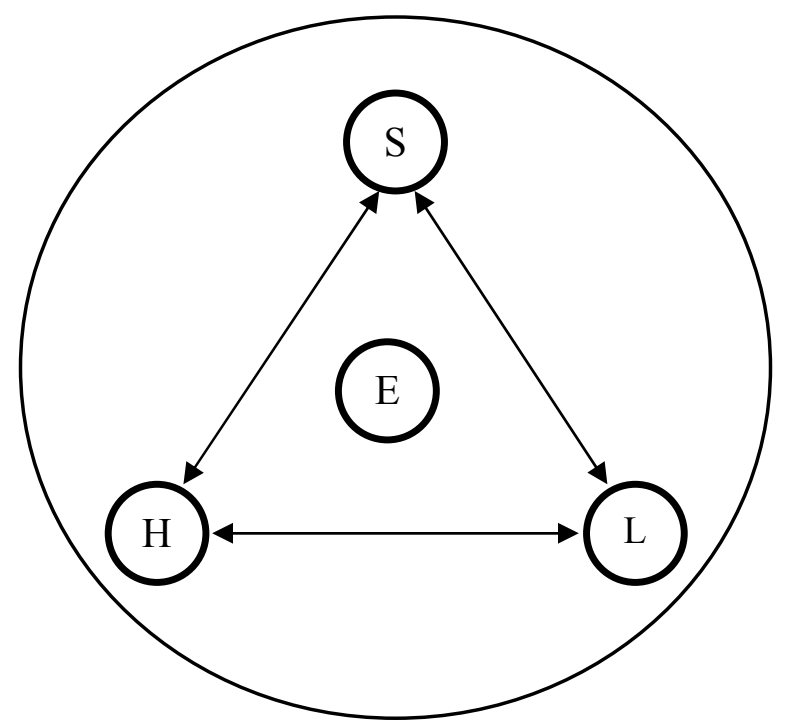

Figure 1. The SHEL Model. From Human Factors In Aviation edited by Earl L. Weiner and David C. Nagel, 1988, p. 15. Copyright 1988 by the Academic Press. Reprinted by permission.

The environment, while not directly connected to the "S", "H", and "L" nodes of the model, includes factors over which no one has control. These include physical, economic, political, and social factors (Wiener \& Nagel, 1988). The connection of the nodes " $S$ " " $H$ " and "L" are known as interfaces. In the case of "L$\mathrm{H}$ ", it is referred to as "Liveware to Hardware Interface". In this paper it will be annotated as: "L-H" or "L-L" in the case of liveware to liveware,

The interactions within the SHEL diagram are a focus of Human Factors research. An example of "L-S" is when a crew of an aircraft has to obey rules, procedures and regulations. These rules can be the Federal Aviation Regulations (FARs), a company's Standard Operating Procedures (SOPs), or just the laws governing the driving to and from work. An example of "L-H" is a cockpit crew operating the controls of an aircraft during a flight. When the pilot reaches for the controls of the airplane and manipulates them in a certain fashion, it's an example of an "L-H" interaction. An example of "H-S" interaction is when an aircraft flies through or into an Air Traffic Control Facility's (ATC) section of airspace. The crew (L) has to follow the rules governing the airspace, but the aircraft must also be capable of maneuvering in accordance with those rules. The engineer's design and the aircraft's capabilities are the key to this interaction. If an aircraft $(\mathrm{H})$ cannot climb to meet the requirement (rules/procedures) of a climb segment on a departure from an airport $(\mathrm{S})$, then there is a conflict between " $\mathrm{H}-\mathrm{S}$ " that commands attention.

There is a system of data collection being used today that can be used with the "E" node of the SHEL diagram. The modified center of the SHEL diagram will be "E/F" rather than just "E". The "F" in the proposed SHEL model stands for Flight Operational Quality Assurance, otherwise known as "FOQA". The FAA regulations state, "FOQA is a voluntary program for the routine collection and analysis of digital flight data for the purpose of identifying adverse safety conditions, and where appropriate, proactively initiating corrective action before such conditions can lead to accidents" (Federal Register, 2002, p. 56771). FOQA's beginning was really in 1958, when the Civil Aeronautics Board mandated that flight data recorders (FDRs) be required equipment on all U.S. registered airliners (GAO, 1997). Although FDRs have been in existence that long, FOQA is a fairly new process. United Airlines has the distinction of having the oldest FOQA program (Kolczynski, 1998). The FAA officially started incorporating FOQA data into its safety programs in 1995 according to the General Accounting Office (GAO, 1997). Figure 2 shows the revised SHEL diagram. 


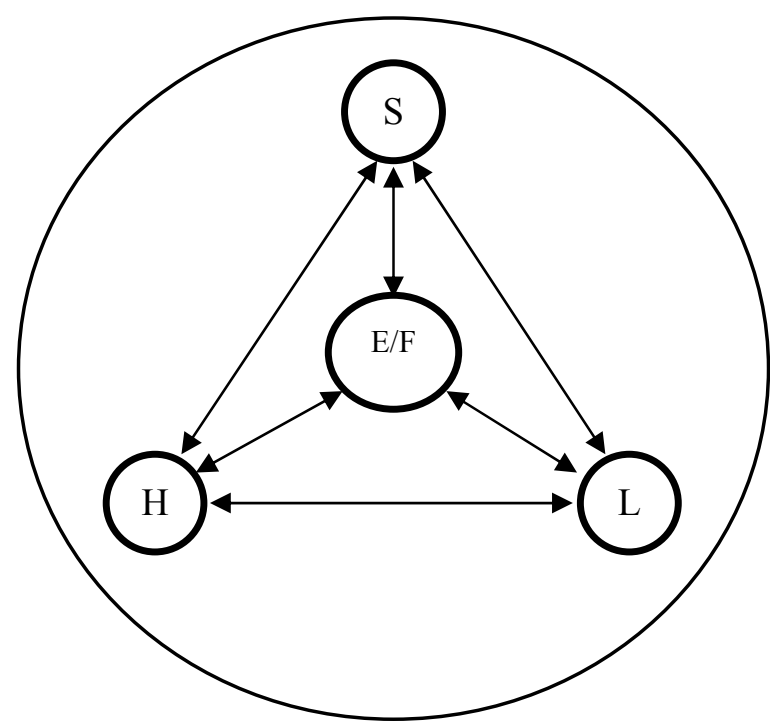

Figure 2. The SHEL Model. From Human Factors In Aviation edited by Earl L. Weiner and David C. Nagel, p. 15. Copyright 1988 by the Academic Press. Reprinted by permission. Modified by the author.

It is difficult to analyze any of the SHEL interactions without data. The FAA and FOQA are making it possible to analyze almost every aspect of commercial aviation, short of analyzing the brain waves of the pilots. Flight data recorders record an enormous amount of data. The performance of the " $\mathrm{H}$ " portion of the SHEL diagram is fairly straightforward. Direct analysis of the flight recorder data has been used for many years in accident investigations around the world. But in order to understand how FOQA assists with the "S" and "L" portions of the diagram, one must first understand FOQA.

FOQA is not a new stand-alone system. FOQA takes flight data and transforms them into information that can be used on a day-to-day basis, rather than for accident investigations as they have historically been used. In the past, the only time data were extracted from an FDR was when an aircraft crashed, or there was a major incident that required FDR data for an investigation. With the advent of miniature electronics and multi-channel FDR's, much more data can be obtained on a regular basis. The FOQA data are obtained by instrumenting the aircraft with numerous sensors in addition to those normally utilized, or by tying into the existing data buses within the aircraft. These sensors feed information into the FOQA recorder data banks for future analysis. Another common practice is to piggyback data from the aircraft's existing FDR. This process is much like hooking jumper cables from one car to another. These devices allow maintenance to download the FDR data easier than removing the FDR from its installed location. Another method is to install a device called a Quick Access Recorder (QAR) in the aircraft. This device is a stand-alone recorder that ties into the aircraft systems to record as many as 900 different parameters. Some QAR's use an optical disk that can store an average of 10 days of flight data before needing to be removed and replaced with a new disk (Cunningham, 1999). Data can also be recorded on magnetic tape devices, or by a process known as "...milking your existing FDR” (Flight Data Services LTD, 2003, p. 2).

Large amounts of data can be gathered very easily with such devices. In a 1997 report to the General Accounting Office pertaining to QAR's, the following was noted:

Flight data recorders may not capture a sufficient number of parameters to be useful for FOQA purposes. Currently the FAA requires from 16 to 29 parameters to be recorded on flight data recorders in transport aircraft; a FOQA program, however, would likely capture many more parameters. Typically, the 200-500 parameters available on modern digital aircraft allow a more comprehensive set of 
conditions to be monitored. Finally, flight data recorders hold about 25 hours of flight data, a relatively short time period. Instead, some U.S. airlines use a device called a quick access recorder (QAR) to record FOQA data to a removable optical disk or Personal Computer Memory Card International Association (PCMCIA) card. QARs record flight data that are output from the aircraft's digital flight data acquisition unit (DFDAU), the same device that feeds parameters to the flight data recorder. On average, QARs can hold from 100 to 200 hours of flight data. (GAO, 1997, p. 22).

There is an enormous amount of data that can be obtained. "On Boeing 737-500 series aircraft, an average of $7.2 \mathrm{Mb}$ of data is obtained per day, that has 329 parameters, resulting in an average of 2.6 Gigabytes of tail number specific data per year" (Davis, 1999).

There are numerous issues regarding FOQA data. The first one is obviously retrieving it. Delta Airline's standard operating procedure (SOP) is to download their FOQA data through the use of maintenance technicians. Delta and the Airline Pilots Association (ALPA) management members meet approximately every seven to ten days to analyze the FOQA data. The team members determined that there are 83 parameters that they look for, ranging from "...excessive rotation rates, pitch rates that were too high or low on takeoff or landing, glide slope deviations during an Instrument Landing System Approach (ILS), excessive descent rates, engine events, and various maintenance events" (Cunningham, 1999, p. 32). This process involves numerous person-hours and a fair amount of coordination to make sure the data are captured for further analysis. One of the easiest ways to capture FQOA data is to do it automatically by transmitting the data each time the aircraft blocks in at the terminal or hangar (Flight Data Services LTD, 2003). With today's wireless network technology and robust computing capabilities, this seems like a reality that's not too distant in the future.

Another problem area is with the FOQA data itself. According to the FAA it is up to each individual airline to determine how they are going to capture, analyze, protect, and disseminate the data. Safety experts and the FAA agree that FOQA data need to be protected from open public distribution (14 CFR CHAPTER I - PART 13.401, 2003). This allows the data to be used to help prevent future safety incidents, and to learn from the past. FAA regulations are in place to accomplish this. According to the FAA, if the FAA Administrator approves an operator's FOQA program, "the FOQA data will not be used for punitive measures against the operator or its employees, unless an incident or accident resulted from a criminal or deliberate act" (14 CFR - CHAPTER I - PART 13.401, 2003, (4e)). Safety experts and the FAA are in agreement that access to FOQA data needs to be restricted except for safety uses (14 CFR CHAPTER I - PART 13.401, 2003).

When the data have been captured in a QAR, retrieved by maintenance, or directly transmitted to an airline's FOQA department, they are analyzed by airline personnel. In the case of Delta Airlines, the QAR disk is sent to Delta's Corporate Safety Office, where it is placed in a guarded location until their FOQA team can analyze the data. So what would qualify as a "FOQA Event", otherwise known as a "flagged event"? The Delta team members examine the data to see if any of the 83 specific events are identified on the QAR. An example of a flagged event would be excessive airspeed on final, glide slope deviation, or an incorrect configuration (Cunningham, 1999). These are much like "bit-balls" in certain aircraft. The indicators merely tell managers, maintenance, or the FOQA team that something has been exceeded.

The Delta FOQA team can select any event they deem necessary during a flight, in the interest of safety. All that's required is a change to the FOQA software, which would enable the capturing and processing of data, pertaining to the event, identified for analysis. The FOQA data are then de-identified or erased by a board member called the gatekeeper (Cunningham, 1999). This is the process that removes the identity of the aircraft's crew, so the data can remain anonymous. It is important that the data not be de-identified if a violation or accident occurs. The FOQA team and the airline's management must also have procedures in place 
to keep the identity of the crew, if they intend to use the data to identify additional training requirements (Cunningham, 1999).

The SHEL model and FOQA can be linked together to help an airline use FOQA to improve the "S"-"H"-"L" interactions to make the skies safer, and more efficient. One accident that might have been avoided if FOQA data had been used was on the evening of March 5, 2000 when a Southwest Airlines 737-300 went off the end of the runway at the Burbank (BUR), California airport. The crew of the mishap aircraft accepted a "slam dunk" approach, which is an approach that is begun very close to the airport, at an altitude that is higher than normal. If flown properly, airspeed can be managed and a safe stabilized approach can be accomplished. This did not happen on the night of this accident. The National Transportation Safety Board (NTSB):

...conducted an airplane performance study in conjunction with this accident investigation. FDR and radar data indicate that the airplane began its final descent to BUR about three $\mathrm{nm}$ from the runway 8 threshold. Taking into account the airplane's altitude of 3,000 feet msl at the beginning of the descent and the 725-foot msl elevation of the touchdown zone (TDZ) on runway 8 , geometry calculations indicate that the airplane would have had to have descended at an average flight path angle of about $7^{\circ}$ to touch down in the runway 8 TDZ. Radar and FDR data show that the airplane descended at an average flight path angle of about $7^{\circ}$ until flare, at an average vertical speed of 2,200 feet per minute (fpm), and at indicated airspeeds of between 182 and 200 knots. The airplane began to flare about 170 feet agl. and flared for about 9 seconds before touching down at 182 knots indicated airspeed on runway 8. Average ground speed during the flare was 195 knots, indicating that the airplane traveled about 3,000 feet during the flare. (NTSB, 2002, p. 12)

The long landing, on a short, wet runway, with a tailwind, and excessively high approach airspeed culminated with the aircraft departing the prepared surface. It is important to note that Runway 8 at Burbank is only 5,801 feet long
(Bob Hope, n.d.). The aircraft came to rest next to a gas station off the airport property.

The high descent angle was the first "FOQA Flag" that should have been triggered during this accident. The NTSB report indicates that:

A comparison of the recorded radar data of the accident airplane to 70 other airplanes that had landed at BUR on runway 8 between 1000 and 2200 on June 13 and 14,2000 , showed that of the 16 airplanes vectored from the north side of BUR to land on runway 8,12 were vectored to intercept the final approach course between 9 and $15 \mathrm{~nm}$ west of the runway threshold. Flight 1455 was given vectors that resulted in interception of the final approach course about eight $\mathrm{nm}$ west of the runway threshold. The comparison also showed that the glide paths of most airplanes approaching runway 8 were between $3^{\circ}$ and $4^{\circ}$. The accident airplane's glide path was $7^{\circ}$. (NTSB, 2002, p. 18)

The second "FOQA Flagged" event would have been the touch down speed in this accident, which according to Southwest Airlines procedures was "Target Speeds". Chapter 3, Section 6 of the procedures, states, in part: "Fly Vref [32] + 5 knots for tailwind landings". The CVR transcript indicates that, at 1804:42, the first officer informed the captain that the target airspeed would be 138 knots" (Aircraft Accident Brief, 2002, p. 14). The touchdown speed of this aircraft was 182 knots with the flaps extended to the 40-degree setting. On this particular version of the Boeing 737-300, the speed that is not to be exceeded with the flap 40-degree setting is 158 knots indicated airspeed (NTSB, 2002). The aircraft's speed for this approach was 44 knots above the target speed of 138 knots and resulted in a flap over-speed of 24 knots to both the flaps and the flap actuating assemblies.

It is important to note the actions of the first officer during this accident. During the approach the first officer:

...also stated that when the captain called for flaps $40^{\circ}$, the airspeed was about 180 knots and went as high as 190 knots during the approach. The first officer indicated that he pointed to his airspeed indicator to 
alert the captain of the flap limit speed of 158 knots at flaps $40^{\circ}$. (NTSB, 2002, p. 4)

The SHEL interactions to look at are the "H"-"S"-"L" interactions of the high descent rate, high airspeed, and lack of following procedures during this approach. Figure 3 is a diagram of an ILS with a 3-degree glide path. The dashed line superimposed on the approach shows a 7-degree glide slope, approximately that of the Southwest flight.

The fix "First" is approximately nine nautical miles from the end of RW17 in this example ILS. This can be used to represent the Southwest flight's final approach segment. Rather than being on the solid line at this notional fix, according to the accident report, the aircraft was on a 7-degree approach glide path, represented by the dashed line. Not only was the aircraft well above glide path, it was being flown with excessive airspeed at this point in the approach. During the Southwest approach, the desired 3 to 4-degree descent gradient was most definitely exceeded.

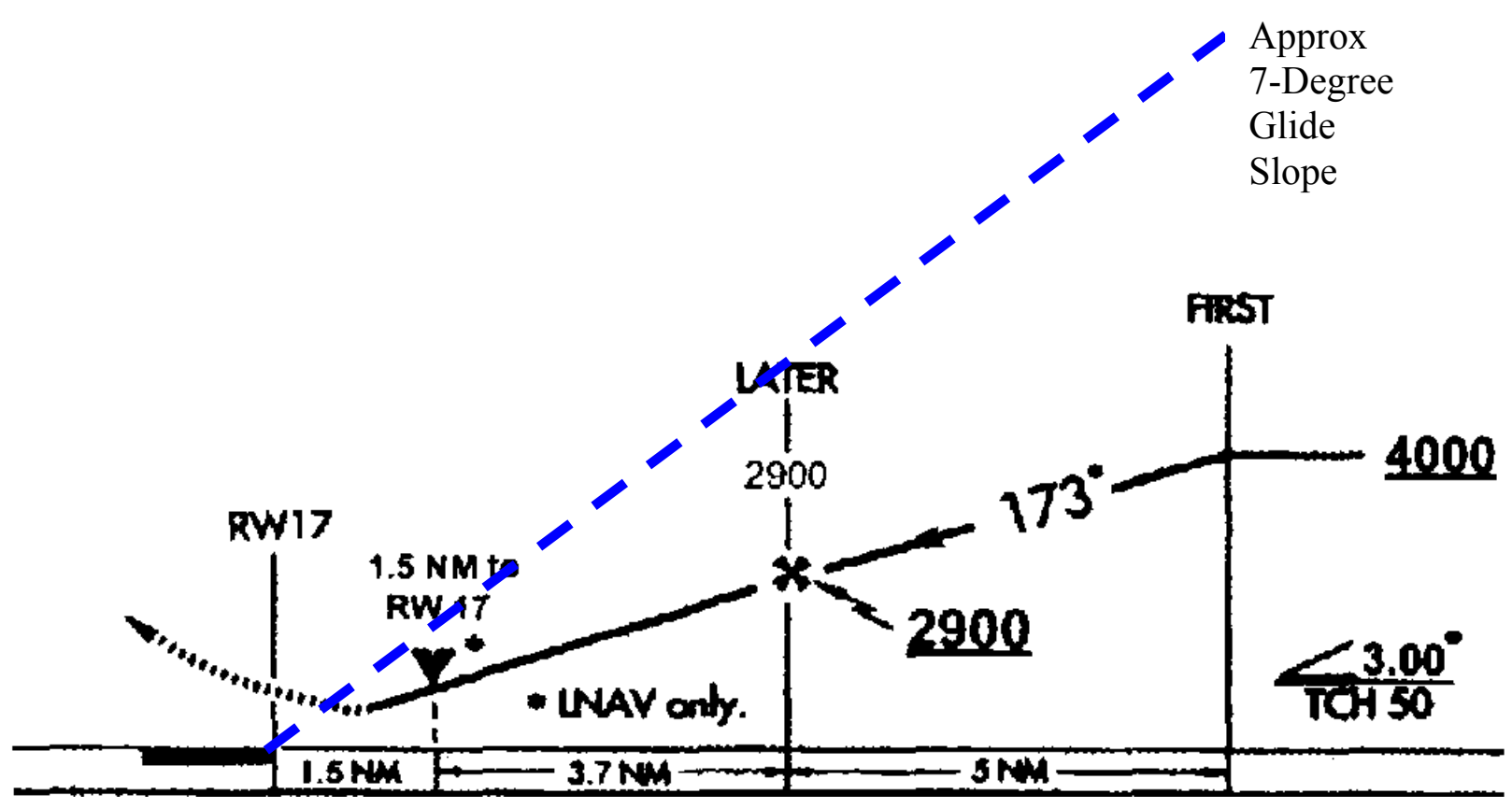

Figure 3. ILS Example. From Airman's Information p. 5-4-11. February 24, 2000 reprinted by permission.

FOQA allows an airline to set windows that will alert the airline if a parameter has been exceeded. One such parameter is stabilized approach criteria, defined at "a predetermined point and beyond the aircraft is "in the window". Different airlines have different parameters. They may include aircraft configuration, speed, minimum power settings, and vertical speed, to name a few. An example might be: "Outer Marker - Aircraft on the localizer and glide slope, gear down, flaps approach, speed less than 140 knots 500 feet above decision height or above touchdown if field in sight - Aircraft still on localizer (loc) and glide slope, gear down, flaps full, speed Vref +15 or less. Note: This is the "window", should your speed vary by 15 knots or more or should you lose the loc or glide slope by one dot, execute a missed approach or go around " (Stabilized Approach n.d., p. 1). Figure 4 shows an airline's procedure for an ILS, which includes call outs, and parameters that should be met at certain points on the approach. There are also target airspeeds and altitudes associated with each of the windows in Figure 4. 


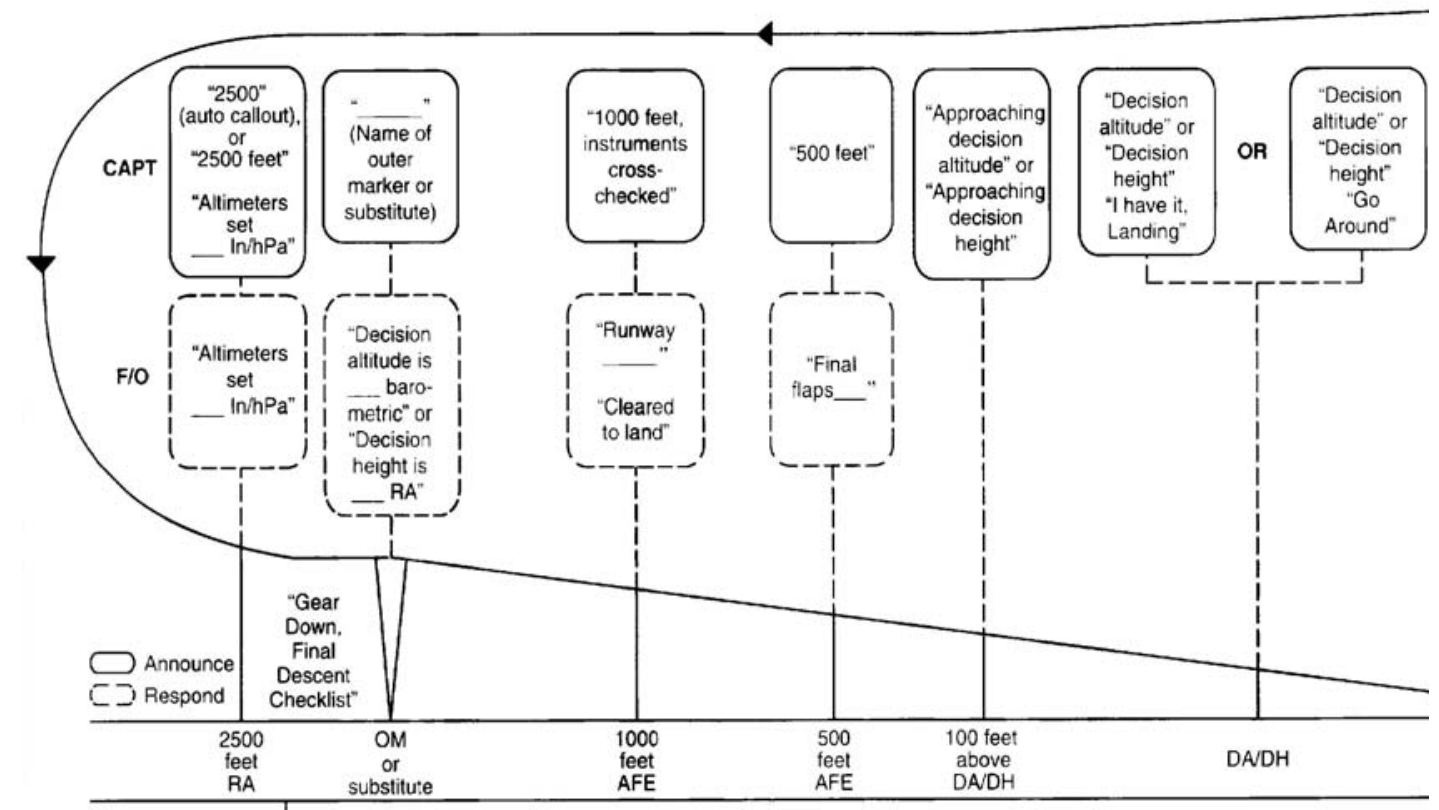

Figure 4. Approach example. From "Flight Operations Manual” February 24, 2000. Reprinted by permission.

By knowing the parameters associated with the approach, FOQA and the FOQA team can set parameters "windows" to look for certain events. Figure 4 shows that by 500 feet agl. the landing flaps are supposed to be in their final position. If the FOQA data shows movement of the flaps below 500 feet agl., as indicated by the radar altimeter, then a FOQA flag should alert the team. If the situation warrants, the crew could be called to figure out what happened. If there was a definite reason for the SOP deviation, one of three things can happen. If the flagged event was a momentary deviation that was situation dependant, the company might overlook the event. If the results of the flagged event are such that the rules need to be changed, then the FARs might require revision. And finally, if the SOPs are not allowing the aircraft or crew to perform correctly, then the SOPs need revised. If the team discovers that the incident warrants further crew training due to poor procedural knowledge, it's better than allowing a situation to develop such as Southwest's Burbank accident.

Take another example; suppose the aircraft was 20 knots fast at the same 500-foot agl. point as in the last example. If a company's SOPs are to be within 5 knots of the bugged target speed, this might indicate a major deviation. If the weather reports indicated nothing to counter the data, remedial training of the crew might be warranted. If the weather reports indicated that there were gusty winds and poor weather on that day at that arrival airport in the flagged event, then the FOQA flagged event might not warrant any further investigation. The analysis must allow for investigation before an event leads to false accusations that a crew performed poorly.

During the NTSB investigation of Southwest's accident at Burbank, they found that probable causes of the accident "... was the flight crew's excessive airspeed and flight path angle during the approach and landing and its failure to abort the approach when stabilized approach criteria were not met" (NTSB, 2002, p. 22 ). The flight crew was not solely responsible for this accident. The NTSB also faulted the Burbank approach controller. The NTSB stated that the "...controller positioned the airplane too fast, too high, and too close to the runway threshold to leave any safe options other than a go-around maneuver" (NTSB, 2002, p. 22).

Numerous " $\mathrm{S}$ " "H" "L" interactions were involved in this accident. "L"-"S" interactions were obviously involved with regard to both approach angle and airspeed. The approach angle of 7-degrees was double what is labeled as 
the accepted norm. The touchdown speed of 182 knots was 44 knots above the target approach speed, and exceeded the flap extension speed for the flap 40-degree setting by 24 knots (NTSB, 2002). Was this an isolated incident, or do incidents like this occur more frequently? Can FOQA and the SHEL model help avoid accidents like this in the future?

FOQA allows airlines to monitor and analyze data on a regular basis, rather than the infrequent schedule of a checkride. FOQA allows continuous monitoring and analysis of the "S"-"H"-"L" interactions that are happening every minute of every day, on every single flight. When a check airman is giving checkrides, crews are more likely to be on a best behavior to perform all duties in accordance with published regulations, company SOPs, and in accordance with the FARs. FOQA allows an airline to monitor and improve procedures when the check airman isn't present. According to Gary Davis, Deputy Division Manager, Air Transportation Division, Flight Standards Service "The vast majority of information gained by FOQA cannot be found in any other way. Periodic line checks conducted by check airmen cannot provide the same level of insight into daily operations as the continuous monitoring of FOQA data. Check rides are a "one look opportunity" (Davis, 1999, s-4). This is the big difference between FOQA data and a check airman. FOQA is there all the time, and through proper analysis and protection it can provide insight to numerous problem areas before they develop into major incidents, or even accidents. This continuous monitoring of SHEL interactions is where airlines are poised to gain the most from FOQA. It should be noted that at the present time, Southwest Airlines does not have an operational FOQA program.

The Southwest accident at Burbank might not have been the only incident of this type at the airport. The FAA cited the controllers as being causal in this accident. The question must be raised then, how many other aircrews were given short vectors to the "slam dunk" approach like this in the past, and just made it work? These "L"-"L" interactions could possibly have been identified by analyzing FOQA data. If FOQA events are indicating that only certain aircrew members are having more FOQA events than others, then aircrew training and or monitoring might be warranted. Additional training could remedy any deficiencies that a specific crew has. This would be an example of a "L" interaction being the focus of attention. This analysis must obviously be done before the FOQA data is de-identified by the FOQA team. The central node "E/F" on Figure 2 would indicate that the problem lies with the "L" node rather than the others, based on the captured data. This requires the FOQA analysis and filters to be highly refined and accurate. If numerous FOQA events are being flagged by an airline, the FOQA data analysis can allow an airline to pin point the problem areas. The FOQA team can analyze the data to identify whether the events are crew, aircraft, weather, or airport specific, rather than taking an educated guess.

If the data identify that a certain aircraft or aircraft fleet type is having issues, the " $\mathrm{H}$ " node in the SHEL model should be the focus of the data analysis, and the team must look at how the aircraft is being operated. Using Burbank as an example, if only a certain aircraft fleet type is having problems stabilizing approaches, and all other types of aircraft are within acceptable standards, then procedures must be modified to take this aircrafts limitations into account. This is an example of modifying or taking the "H""S" interactions into account. By changing the procedures, the way the aircraft is operated, or the rules that air traffic control uses for this aircraft type, the limitation can be accommodated to allow the aircraft to operate safety.

The NTSB cited the controllers at fault in the Burbank accident. If FOQA data from numerous fleets and airlines could have identified that all fleets, crews, and airlines were having difficulty with the arrival procedures into the airport the procedures the air traffic controllers were using could have been modified to make them safer. Ultimately, the crew in the Southwest accident was guilty of the most basic fact in flying an aircraft; if the approach does not look right, then "go-around." During the course of the approach, the crew failed to put together the pieces of the puzzle that should have led to an eventual go-around from the approach. The co-pilot made mention of the excessive speed, even pointed to the airspeed indicator, but failed 
in forcing the issue of executing a missed approach. One tactic might have been to state "Southwest 123 is executing a missed approach" over the radio. This might have finally clued the captain into the fact that he needed to execute a missed approach rather than prosecuting a flawed approach and landing. Ultimately, the crew must make the right decision within the SHEL model.

The "L"-"L" interactions are difficult to monitor other than through the cockpit voice recorder. Current regulations do not allow cameras in the cockpit. Crew Resource Management (CRM) classes and seminars are held to reenact incidents such as the Southwest accident. This is an excellent place to chair fly just such incidents. During CRM seminars, and even at home, a cockpit crewmember can think about scenarios and about what he or she will do during such an event.

Airlines can benefit in more that just the operations department. The maintenance department can reap enormous benefits from FOQA. Take for instance an event known as a flap overspeed. This event occurs when the aircraft exceeds the manufacturer's placarded speed for a specific flap setting, otherwise known as flap position. For instance, in Southwest's accident aircraft the maximum airspeed limit for a flap setting of 40-degrees was 158 knots indicated airspeed (NTSB, 2002). If this speed is exceeded, maintenance should inspect the aircraft for damage. If this speed is exceeded excessively, serious damage to the aircraft is possible. The problem arises when these incidents occur repeatedly, by just a few knots, or a one time excessive overspeed, such as the Southwest incident, without the incident being entered into the maintenance forms. Over time, if not inspected and repaired, occurrences like this one introduce fatigue and stress cracks throughout the aircraft structure.

An incident like this results in the greatest FOQA benefit for an airline's maintenance and safety department. At Delta, if management and the FOQA teams identify an incident, a miniinvestigation subsequently occurs. If the event identified by FOQA was entered into the aircraft forms, and maintenance cleared the entry, or is in the process of working the issue, no further action is taken. If the event was not cleared by maintenance, or was not entered into the aircraft forms, the team makes the following maintenance entry in the logbook "discovered by FOQA" (Cunningham, 1999, p. 32). Using the flap overspeed scenario as an example, Delta's procedures dictate that if the overspeed exceeded the placarded limit by less than 15 knots, the aircraft can remain in scheduled service until the next scheduled 100-hour inspection. If the overspeed was 15 knots or greater, then the aircraft is grounded and removed from scheduled passenger revenue service until it can be inspected (Cunningham, 1999).

Without FOQA, the safety system relies completely on the integrity of aircraft crews to realize and admit to exceeding the limits of various aircraft systems whether intentionally or unintentionally. Overspeeds are very serious and can be caused by crews that truly didn't notice the overspeed, possibly due to task saturation, or lack of situational awareness. FOQA can help an airline's maintenance department perform only the necessary maintenance, and identify major maintenance required. This is an example of all the nodes of the SHEL model being affected by the "E/F" node. Causing the incident or performing the maintenance action to correct the problem affects the human "L" directly or indirectly. The aircraft " $\mathrm{H}$ " is involved because it was damaged or required maintenance. The rules and procedures " $\mathrm{S}$ " were an issue because they were not recognized, followed, or were not sufficient to prevent the incident from happening.

An example of an S"-"H"-"L" failure that FOQA might have been able to help identify was the 1982 accident of an Air Florida 737-200 on January 13, 1982. One of the accident's causes was the "flight crew's failure to use engine anti-ice during ground operations and takeoff, their decision to take off with snow/ice on the airfoil surfaces of the aircraft, and the captain's failure to reject the takeoff during the early stage when his attention was called to anomalous engine readings" (NTSB, 1982, p. ii). The NTSB found that the flight crew had not used engine anti-ice during ground operations. The buildup of snow and ice on the aircraft, and in particular on the engine pressure probes, were the major causes of this accident. The blocked 
pressure probes caused incorrect engine thrust readings. The artificially high pressure readings for a given throttle setting caused the crew to actually set a lower power setting and corresponding throttle position, resulting in insufficient thrust being produced to sustain flight. The low power setting and buildup of snow and ice on the aircraft prevented the aircraft from generating the lift required to sustain flight (NTSB, 1982).

Aircraft engines require anti-ice for certain operations in cold weather. FOQA and its data could have helped prevent the Air Florida accident. Anti-ice rules and procedures " $S$ " have been changed since this accident (NTSB, 1982). Rules are now in place that governs how long an aircraft can sit on the ramp after being deiced. The times vary depending on what type of deicing fluid is used. "S", "H", and "L" interactions were all modified together by using the N1 (engine RPM) gauges in addition to the (EPR) exhaust pressure ratio gauges to set engine thrust levels. Procedures are now in place " $\mathrm{S}$ " so if one gauge fails or is reading incorrectly, the engine thrust can be set correctly using the other indication. This cross checking of engine instruments ensures that engine operation is what the crew expects. FOQA data might have shown that Air Florida was not turning on the engine anti-ice when temperatures were below a preset level. If this data could have come to light, training procedures could have been altered so the crew "L" actions could be changed prior to the accident, possibly avoiding the accident entirely. Wouldn't it have been great to listen to FOQA rather than allowing the environment to influence this accident?

In 1958, when the Civil Aeronautics Board mandated that all commercial airliners must have flight data recorders, FOQA was born. FOQA has been in its infancy since then. Technology changed rapidly during the 1970's with the introduction of the Traffic Collision Avoidance System (TCAS), the Ground Proximity Warning System (GPWS), and Cockpit Resource Management (CRM) programs. All of these programs were identified as problem areas, which impacted the national airspace system. Experts have noticed that FOQA has great potential and is "One of the yet un-exploited tools" (Brandt, 1999, p. 1). It has capabilities that can revolutionize how humans interact with their environment and the machines that they operate within that environment. One of the biggest challenges that face airlines, unions, and lawmakers is data protection. In order for FOQA data to be used to its fullest potential, it must be protected much like the NASA system that's in place to report pilot deviations and admissions. The difference between them is that NASA's system relies on pilots to self-disclose information. FOQA is monitoring all the time, everyday. All we have to do is look at the data and make the appropriate changes.

Today's airline environment is very competitive. No one can afford to operate inefficiently or in an unsafe manner. FOQA provides a tool that can revolutionize the safety system, the SHEL model, and the interaction of man, machine, and his environment. Even the Wright Flyer had FOQA on board; it just took Orville and Wilbur a lot of time to try to remember what happened on the short flights. They would have loved to have the tools available today to monitor and analyze flight operations. 


\section{REFERENCES}

Bob Hope Airport Burbank, California, USA. (n.d.) Retrieved May 2, 2004, from http://www.airnav.com/ airport/KBUR

Cunningham, B. (1999). FOQA update. The widget, January/February 1999, 31-32. Retrieved April 3, 2004, from http://www.dalpa.com/public/widget/fall99/foqa.pdf

Davis, G. (1999). Flight operational quality assurance (FOQA). Retrieved April 27, 2004, from Federal Aviation Administration, Deputy Division Manager, Air Transportation Division, Flight Standards Service Web site: http://www.ntsb.gov/events/symp_rec/proceedings/ May_4/SessionII/Pres_Davis.ppt

Federal Register / Vol. 67, No. 172 (2003, July 1). Proposed Rules, Department of Transportation, Federal Aviation Administration, 14 CFR - Chapter I - Part 13,subpart 401. Retrieved July 8, 2003, from http://ecfrback.access.gpo.gov/otcgi/cfr/otfilter.cgi DB=1\&ACTION=VIEW \&QUERY $=13.401$

Federal Register / Vol. 67, No. 172. (2002, September 5). Proposed Rules, Department of Transportation, Federal Aviation Administration, 14 CFR Part 193. Retrieved July 8, 2003, from http://www.asy.faa.gov/gain/FOQA_\&_ASAP/part193_designations.htm

Frequently asked questions by Flight Data Services Ltd. (n.d.). Retrieved July 7, 2003, from http://www.flightdataservices.co.uk/faqs.php

Kolczynski, P. (1998, April). FOQA: Are legal issues interfering with safety improvements? Retrieved July 1, 2003, from http://www.aviationlawcorp.com/content/foqasafety.htm (AVweb, 1998)

National Transportation Safety Board. (1982, January 13). Aircraft accident report of Air Florida Inc. flight 90, collision with $14^{\text {th }}$ street bridge near Washington National Airport, Washington, D.C. Retrieved May 1, 2004, from http://amelia.db.erau.edu/reports/ntsb/aar/AAR82-08.pdf

National Transportation Safety Board. (2002, June 26). Aircraft Accident Brief of Southwest Airlines flight 1455. Retrieved July 9, 2003, from http://www.ntsb.gov/publictn/2002/AAB0204.pdf

National Transportation Safety Board. (1999, May 5). International symposium on transport recorders, The next generation FOQA programs. Retrieved July 9, 2003, from www.ntsb.gov/ events/symp_rec/proceedings/ authors/brandt.pdf Patrizia, M., Paola, L., \& Francesco, P. (Extended Abstract for ATM R\&D Seminar 2001). Evaluating safety and usability of ATM systems. Retrieved April 12, 2004, from http://www.dblue.it/pdf/Evaluating_Safety_and_Usability.pdf

Stabilized Approach. (n.d.). Retrieved April 17, 2004, Procockpit.com, from http://www.procockpit.com/ stabilizedapproach.htm

United States General Accounting Office. (1997, December 2). Aviation Safety, Efforts to Implement Flight Operational Quality Assurance Programs. Retrieved July 9, 2003, from http://www.gao.gov/ archive/1998/rc98010.pdf

Wiener, E., \& Nagel D. (1988). Human factors in aviation. San-Diego: Academic Press. 